\title{
A decade of emerging indications: deep brain stimulation in the United States
}

\author{
Brett E. Youngerman, MD, ${ }^{1}$ Andrew K. Chan, MD, ${ }^{2}$ Charles B. Mikell, MD, ${ }^{1}$ Guy M. McKhann, MD, ${ }^{1}$ \\ and Sameer A. Sheth, MD, PhD'
} 1Department of Neurological Surgery, Columbia University Medical Center, New York, New York; and 2Department of
Neurological Surgery, University of California, San Francisco, California

\begin{abstract}
OBJECTIVE Deep brain stimulation (DBS) is an emerging treatment option for an expanding set of neurological and psychiatric diseases. Despite growing enthusiasm, the patterns and implications of this rapid adoption are largely unknown. National trends in DBS surgery performed for all indications between 2002 and 2011 are reported.
\end{abstract}

METHODS Using a national database of hospital discharges, admissions for DBS for 14 indications were identified and categorized as either FDA approved, humanitarian device exempt (HDE), or emerging. Trends over time were examined, differences were analyzed by univariate analyses, and outcomes were analyzed by hierarchical regression analyses.

RESULTS Between 2002 and 2011, there were an estimated 30,490 discharges following DBS for approved indications, 1647 for HDE indications, and 2014 for emerging indications. The volume for HDE and emerging indications grew at $36.1 \%$ annually in comparison with $7.0 \%$ for approved indications. DBS for emerging indications occurred at hospitals with more neurosurgeons and neurologists locally, but not necessarily at those with the highest DBS caseloads. Patients treated for HDE and emerging indications were younger with lower comorbidity scores. HDE and emerging indications were associated with greater rates of reported complications, longer lengths of stay, and greater total costs.

CONCLUSIONS DBS for HDE and emerging indications underwent rapid growth in the last decade, and it is not exclusively the most experienced DBS practitioners leading the charge to treat the newest indications. Surgeons may be selecting younger and healthier patients for their early experiences. Differences in reported complication rates warrant further attention and additional costs should be anticipated as surgeons gain experience with new patient populations and targets.

http://thejns.org/doi/abs/10.3171/2015.7.JNS142599

KEY WORDS deep brain stimulation; neuromodulation; practice patterns; Nationwide Inpatient Sample; technology; functional neurosurgery

$\mathrm{D}$ EEP brain stimulation (DBS) has become an important treatment option for the long-term management of various neurological and psychiatric disorders. Originally approved by the FDA for essential tremor (ET) in 1997, DBS has since received FDA approval for Parkinson disease (PD) (2002) and humanitarian device exemptions (HDE) for dystonia (2003) and obsessive-compulsive disorder (OCD) (2009). Indeed, multiple randomized clinical trials have shown DBS to be more effective than the best medical management in well-selected patients with $\mathrm{PD}^{8,50,61,64}$ and efficacious for medically refractory ET, ${ }^{30,46,51,52,57}$ dystonia, ${ }^{27-29,31,32,45,59,60}$ and OCD. ${ }^{7,17,18,22,37,43,44}$ The early success of approved and exempted indications has led to the investigational and off-label use of DBS to treat a variety of other emerging indications, including pain, ${ }^{2,5,14}$ major depression, $, 3,4,21,26,35,36,38$ Tourette syndrome and other tic disorders,,${ }^{1,6,9,48,53}$ obesity, ${ }^{62}$ anorexia, ${ }^{34}$ substance addiction, ${ }^{42}$ epilepsy, ${ }^{13,15}$ pathological aggression, ${ }^{58}$ dementia, ${ }^{19,33}$ and other movement disorders. . $^{10,63}$

As DBS for HDE and emerging indications is under-

ABBREVIATIONS ARF = Area Resource File; DBS = deep brain stimulation; ET = essential tremor; HCUP = Healthcare Cost and Utilization Project; HDE = humanitarian device exempt; LOS = length of stay; NIS = Nationwide Inpatient Sample; OCD = obsessive-compulsive disorder; PD = Parkinson disease.

SUBMITTED November 13, 2014. ACCEPTED July 15, 2015.

INCLUDE WHEN CITING Published online January 1, 2016; DOI: 10.3171/2015.7.JNS142599. 
taken relatively infrequently, little is known about 1) the actual rates of adoption for specific indications, 2) patient and provider characteristics, and 3) implications for procedural safety or outcomes. To better inform clinicians and researchers about current practice patterns, as well as potential differences in procedural safety and outcomes, large-sample studies are necessary. To this end, we examined the Nationwide Inpatient Sample (NIS), an all-payer, nonfederal hospital discharge database, to trend and compare DBS for FDA-approved, HDE, and emerging indications from 2002 through 2011.

\section{Methods \\ Patient Population}

Data were collected from the NIS (Healthcare Cost and Utilization Project [HCUP], Agency for Healthcare Research and Quality), ${ }^{56}$ a stratified sample of all patient discharges from approximately $20 \%$ of nonfederal hospitals in the United States from 2002 to 2011. Each discharge in the data set is weighted by HCUP to extrapolate the total annual patient discharge information. Discharges utilizing DBS were identified using ICD-9 procedure code 02.93 (implantation or replacement of intracranial neurostimulator lead[s]). All primary diagnosis codes were then reviewed and categorized into 1 of 14 diagnostic groups. For further analysis, primary PD and ET were categorized as FDA approved, dystonia and OCD were categorized as HDE, and all other diagnoses were categorized as emerging. The epilepsy diagnosis codes were excluded because it was not possible to distinguish between DBS implants and other electrode implants. Procedures with no associated primary diagnosis code and codes not corresponding to any published indication were excluded.

We combined data from the NIS with the Area Resource File (ARF), ${ }^{49}$ a basic county-specific database containing more than 6000 socioeconomic and environmental variables for each of the nation's counties. ARF provides data detailing the number of neurologists and neurosurgeons by county, among other variables. We linked the most recent ARF file (2011-2012) by the county Federal Information Processing Standard code to the NIS discharge data in accordance with a previously described method. ${ }^{41}$ This approach allowed the most recent and extensive information regarding neurologist and neurosurgeon density (2010) to be matched to the NIS dataset (2002-2011). The relative neurologist and neurosurgeon county-wide densities did not significantly fluctuate across different years within ARF (range of average density 4.29-4.74 neurologists/100,000 individuals and 1.66-1.76 neurosurgeons $/ 100,000$ individuals; $\mathrm{p}=0.69$ and $\mathrm{p}=0.84$, respectively; 2-tailed t-test).

\section{Patient Characteristics}

The ICD-9 primary diagnosis code, age, sex, modified comorbidity score, race, income quartile of the patient's ZIP code, and form of payment for hospital admission were extracted from the NIS database. NIS provides data for the primary and secondary payers for each patient discharge. We combined both categories of payers into 1 of 4 mutually exclusive categories: "private insurance," "Med- icaid without private insurance," "Medicare with neither private insurance nor Medicaid," and "other." NIS provides 6 categories for race/ethnicity: "White," "Black," "Hispanic," "Asian/Pacific Islander," "Native American," and "Other." Medical comorbidities were defined using a modified version of the Elixhauser Comorbidity Index. ${ }^{11}$ This score is an assessment of the general comorbidity associated with a given patient, which includes a set of 30 comorbidity markers. We used a previously described ${ }^{12}$ modification of the score, which excluded 2 neurological comorbidity variables-"other neurological deficit" and "paralysis"- so the highest possible comorbidity score was 28.

\section{Hospital Characteristics}

Hospital bedsize (small, medium, large), region (Northeast, Midwest, South, West), setting (urban or rural), teaching hospital status, experience (number of discharges by the hospital for ICD-9 procedure code 02.93), and densities of neurologists and neurological surgeons by hospital county were identified in the ARF and NIS databases.

\section{Outcomes}

We examined 5 outcomes: complications, mortality, discharge disposition, length of stay (LOS), and hospital charges. We identified a number of potential complications resulting from DBS surgery, including hematoma, hemorrhage, and infarction (997.00-997.09 and 998.1-998.13), infectious complications related to a mechanical device (996.63), mechanical complications related to a neurological device (996.2), lead removal (01.22), and general surgical complications, including pneumonia (997.32), urinary tract infection (599.0), and deep venous thrombosis/ pulmonary embolism (415.11, 415.19, and 415.40-415.42). The presence of any of these complications was included as an outcome variable we created called "any complication." We report discharge disposition by individual destination and non-home discharges, which is a sum of the short-term hospital transfers, other transfers (including skilled nursing facilities), and death. In addition to LOS, we examined the date of the primary procedure relative to admission in order to isolate group differences in postoperative LOS. Total charges were adjusted based on LOS in order to determine the charges per day.

\section{Statistical Analyses}

The univariate analyses used the Mann-Whitney U-tests and chi-square tests using built-in and custom MATLAB scripts (MathWorks). Hierarchical regression models (SAS procedure GLIMMIX and MIXED; SAS Institute) were used to analyze the variables that predicted outcomes. Predictor variables included age, sex, modified comorbidity score, the presence of any complication, race, income quartile of the patient's zip code, payer status, hospital's level of experience, hospital bedsize, region, setting (urban or rural), teaching status, year of discharge, and type of DBS indication (approved or emerging). Complete case analysis was used. The unique hospital identification code served as the nesting variable, and $\mathrm{p}$ value $<0.05$ was considered statistically significant. Bonferroni correction 
for multiple comparisons was used as appropriate. Statistics are reported by sample mean \pm standard error of the mean.

\section{Results}

\section{Volume of DBS Surgery}

From 2002 to 2011, there were an estimated 1648 discharges for HDE indications and 2014 discharges for emerging indications that received DBS at nonfederal hospitals in the United States. During the same time period, there were 30,490 discharges for FDA-approved indications. Table 1 provides the estimated number of discharges for each primary diagnosis group and the associated ICD9 primary diagnosis codes. Figure 1 shows the discharges by year from 2002 to 2011 for approved and HDE/emerging indications. The volume of DBS surgeries grew rapidly for HDE and emerging indications, with a combined least-squares fitted average annual rate of growth of $36.1 \%$ in comparison with $7.0 \%$ for PD and ET.

\section{Patient Characteristics}

Patients undergoing DBS for HDE and emerging indications were, on average, younger (41.2 \pm 1.1 and 52.1 \pm 0.9 vs $64.3 \pm 0.2$ years of age, respectively; $p<0.0001)$ with lower modified comorbidity scores $(0.65 \pm 0.05$ and $0.84 \pm 0.05$ vs $0.97 \pm 0.01$, respectively; $p<0.0001)$ in comparison with those with FDA-approved indications (Table 2). They were also more likely to be female and either black or Hispanic. There was no significant difference in patient income between groups.

The average age for each emerging indication was younger than that for either PD $(63.8 \pm 0.2$ years $)$ or ET $(65.9 \pm 0.4$ years $)$. The youngest patients were those undergoing DBS for Tourette syndrome and other tic disorders (31.3 \pm 2.4 years), dystonia (41.1 \pm 1.1 years), multiple

TABLE 1. Volume of discharges for DBS by primary diagnosis

\begin{tabular}{|c|c|c|}
\hline Group & ICD-9 Primary Diagnosis Codes & $\begin{array}{c}\text { Estimated No. of } \\
\text { Discharges (2002-2011) }\end{array}$ \\
\hline FDA-approved indications & & 30,490 \\
\hline PD & 332.0 & 23,713 \\
\hline ET & 331.1 & 6777 \\
\hline HDE indications & & 1647 \\
\hline \multirow[t]{3}{*}{ Dystonia } & Torsion dystonia $(333.6,333.7,333.79,333.89)$ & 1600 \\
\hline & Orofacial dyskinesia (333.82) & \\
\hline & Torticollis $(333.83,723.5)$ & \\
\hline OCD & 300.3 & 47 \\
\hline Emerging indications & & 2014 \\
\hline \multirow[t]{7}{*}{ Other movement disorders } & Dementia w/ Lewy bodies (331.82) & 870 \\
\hline & Other degenerative diseases of the basal ganglia (333.0) & \\
\hline & Secondary Parkinsonism (333.21) & \\
\hline & Huntington's \& other chorea $(333.4,333.5)$ & \\
\hline & Athetoid cerebral palsy (333.71) & \\
\hline & Dystonia \& dyskinesia due to drugs $(333.72,333.85)$ & \\
\hline & Other involuntary movement disorders $(333.90,333.99,334.1,334.3,781.0)$ & \\
\hline \multirow[t]{4}{*}{ Pain } & Reflex sympathetic dystrophy $(337.21,337.22,337.29)$ & 480 \\
\hline & Central \& chronic pain syndromes $(338.0,338.29,338.4)$ & \\
\hline & Headache \& migraines $(339.22,339.89,346.20,346.21,346.80,346.91,784.0)$ & \\
\hline & Trigeminal neuralgia \& face pain $(350.1,350.2)$ & \\
\hline Cerebrovascular disease (late effects) & $438.11,438.20,438.21,438.22,438.21,438.30,438.53,438.81,438.89$ & 214 \\
\hline Multiple sclerosis & 340 & 196 \\
\hline \multirow[t]{2}{*}{ Tourette syndrome \& other tic disorders } & Other tic disorder (307.20) & 123 \\
\hline & Tourette disorder (307.23) & \\
\hline \multirow[t]{3}{*}{ Depression } & Major depression disorders $(296.20,296.30,296.33)$ & 95 \\
\hline & Dysthymic disorder (300.4) & \\
\hline & Other depressive disorder (311) & \\
\hline Alzheimer's disease & 331.0 & 20 \\
\hline Conduct disorder & Intermittent explosive disorder (312.34) & 6 \\
\hline Obesity & Morbid obesity (278.01) & 5 \\
\hline Tinnitus & 388.30 & 5 \\
\hline Total & & 34,151 \\
\hline
\end{tabular}




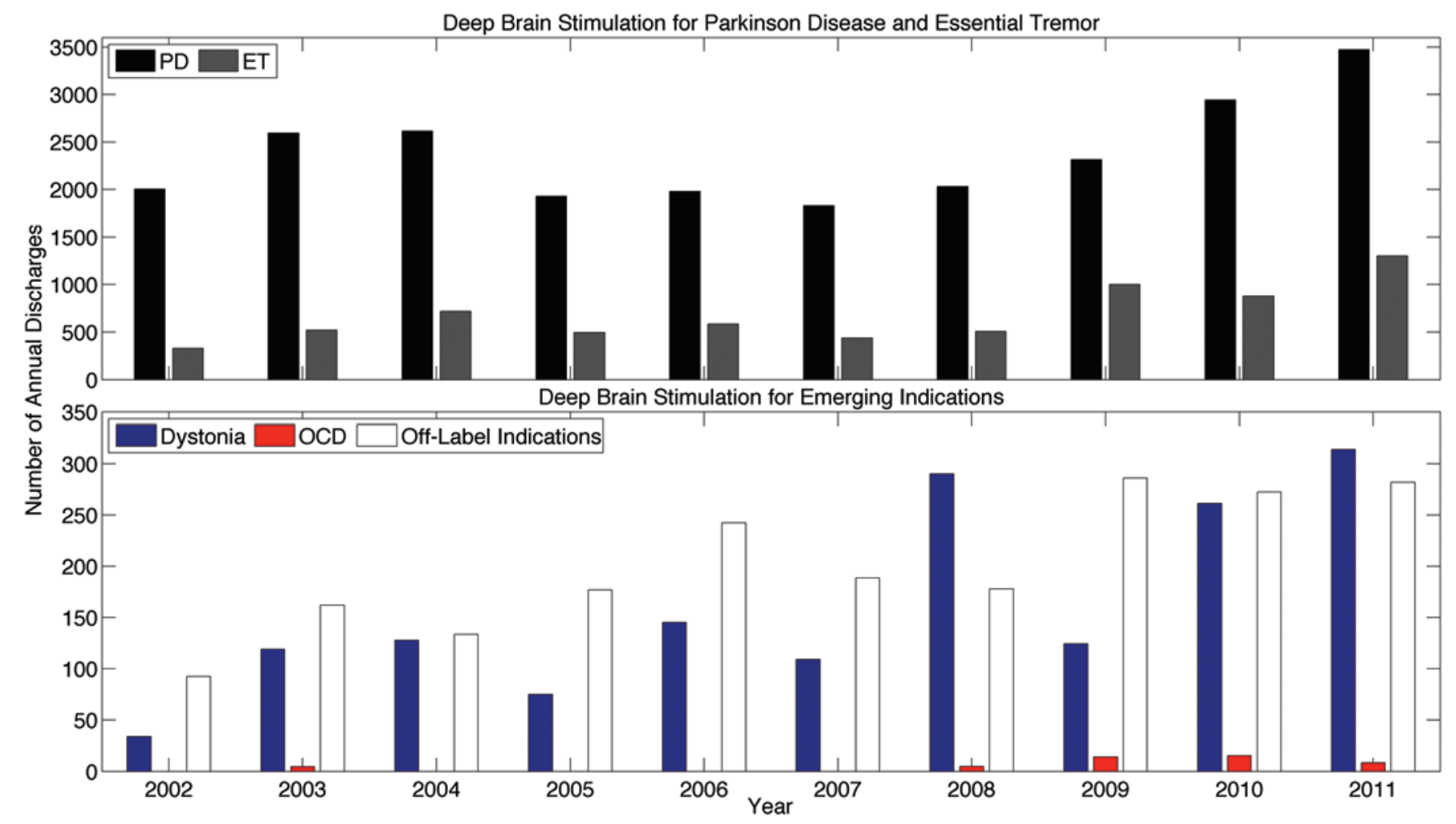

FIG. 1. Volume of DBS procedures for approved and emerging indications in the United States (2002-2011). Figure is available in color online only.

sclerosis ( $44.9 \pm 1.9$ years), or OCD ( $45.8 \pm 4.9$ years). The oldest were those with the late effects of cerebrovascular disease $(57.7 \pm 2.6$ years $)$ and other movement disorders $(57.0 \pm 1.4$ years $)$.

\section{Hospital Characteristics}

Table 2 shows the differences in hospital characteristics between DBS patients for FDA-approved, HDE, or emerging indications. DBS for HDE indications was performed at hospitals with higher annual DBS caseloads $(54.5 \pm 1.8)$ in comparison with both FDA-approved $(41.8 \pm 0.4)$ and emerging indications $(39.5 \pm 1.6)(\mathrm{p}<0.0001)$. The overall DBS caseloads were highest at hospitals that performed DBS for OCD $(82.3 \pm 20.5)$, depression (60.1 \pm 14.3$)$, and dystonia $(53.6 \pm 1.8)$. Of note, caseloads were significantly below average at hospitals that performed DBS for the late effects of cerebrovascular disease $(27.9 \pm 3.3)$ and pain $(33.1 \pm 3.0)$.

HDE and emerging indications were both treated at hospitals with higher county densities of neurologists and neurosurgeons. DBS is performed largely at teaching hospitals for FDA-approved (87.3\%), HDE (94.3\%), and emerging indications $(90.7 \%)$.

\section{Complications and Discharge Disposition}

Table 2 demonstrates the discharge outcomes for the comparison groups. By the univariate analysis, patients undergoing DBS for HDE and emerging indications had notably higher reported rates of any complication $(6.0 \%$ and $5.6 \%$ vs $3.4 \%$; $\mathrm{p}<0.001$ ), and in the multivariate analysis HDE indication was independently associated with complications (OR 2.12; 95\% CI 1.10-4.09; $\mathrm{p}=0.02$ ) (Table 3). The only other independent predictor of complications was an increased comorbidity score. Of note, no hospital characteristics were protective against complications in this analysis.

The higher reported complication rates for HDE and emerging indications (6.0\% and 5.6\%, respectively) in comparison with FDA-approved indications $(3.4 \%)$ was driven by the higher rates of hematoma, hemorrhage, or infarction (3.3\% and $1.6 \%$ vs $1.1 \%)$, mechanical complications $(0.6 \%$ and $0.7 \%$ vs $0.3 \%)$, and lead removal on the same admission $(0.0 \%$ and $1.9 \%$ vs $0.3 \%)$. The rates of any complication were highest for pain $(8.5 \%)$, late complications of cerebrovascular disease $(6.2 \%)$, dystonia $(6.2 \%)$, and other movement disorders (5.7\%). The high complication rates for pain and cerebrovascular disease were driven largely by lead removal (3.4\% and $6.2 \%$, respectively). Dystonia patients had notably high reported rates of hemorrhage or infarction (3.3\%), mechanical complications $(0.6 \%)$, and infections during admission $(0.4 \%)$.

HDE indications had lower rates of non-home discharge $(3.5 \%)$ in comparison with both emerging and FDA-approved indications (6.8\% and 6.0\%, respectively), and emerging indications were independently associated with non-home discharge in the multivariate model (OR 1.77; 95\% CI 1.06-2.96; $\mathrm{p}=0.03$ ) (Table 3). Other independent risk factors for non-home discharges included increased age, higher comorbidity score, Hispanic ethnicity, 
TABLE 2. Comparison between FDA-approved, HDE, and emerging indications (2002-2011)

\begin{tabular}{|c|c|c|c|}
\hline Discharge Characteristics & $\begin{array}{l}\text { FDA-Approved } \\
\text { Indications }\end{array}$ & HDE Indications & $\begin{array}{l}\text { Emerging } \\
\text { Indications }\end{array}$ \\
\hline \multicolumn{4}{|l|}{ Patient characteristics } \\
\hline Mean age $\pm \mathrm{SEM}^{*}$ & $64.3 \pm 0.2$ & $41.2 \pm 1.1$ & $52.1 \pm 0.9$ \\
\hline Mean modified comorbidity \pm SEM ${ }^{*}$ & $0.97 \pm 0.01$ & $0.65 \pm 0.05$ & $0.84 \pm 0.05$ \\
\hline Female $(\%)^{*}$ & 34.7 & 46.6 & 42.8 \\
\hline \multicolumn{4}{|l|}{ Race/ethnicity (\%)* } \\
\hline White & 86.7 & 84.4 & 83.6 \\
\hline Black & 1.4 & 3.4 & 3.7 \\
\hline Hispanic & 6.3 & 7.8 & 8.5 \\
\hline Asian/Pacific Islander & 2.1 & 1.1 & 1.2 \\
\hline Native American & 0.3 & 0.0 & 0.0 \\
\hline Other & 3.2 & 3.3 & 3.0 \\
\hline \multicolumn{4}{|l|}{ Patient income by residential ZIP code (\%)* } \\
\hline 1st income quartile (lowest) & 17.1 & 19.7 & 13.4 \\
\hline 2nd income quartile & 24.6 & 26.0 & 22.0 \\
\hline 3rd income quartile & 27.2 & 27.2 & 29.8 \\
\hline 4th income quartile (highest) & 31.1 & 27.1 & 34.8 \\
\hline \multicolumn{4}{|l|}{ Payment method (\%) ${ }^{*}$} \\
\hline Private insurance & 50.1 & 51.2 & 50.8 \\
\hline Medicaid w/o private insurance & 5.2 & 15.4 & 9.7 \\
\hline Medicare w/ neither private insurance nor Medicaid & 42.1 & 28.5 & 28.4 \\
\hline No Medicaid, Medicare, or private insurance & 2.5 & 5.0 & 11.1 \\
\hline \multicolumn{4}{|l|}{ Hospital characteristics } \\
\hline Mean annual DBS caseload \pm SEM ${ }^{*}$ & $41.8 \pm 0.4$ & $54.5 \pm 1.8$ & $39.5 \pm 1.6$ \\
\hline Mean neurosurgeon density in the county of the hospital \pm SEM ${ }^{*}$ & $51.8 \pm 0.6$ & $61.8 \pm 2.7$ & $58.5 \pm 2.7$ \\
\hline Mean neurologist density in the county of the hospital \pm SEM $^{*}$ & $140.7 \pm 1.8$ & $180.6 \pm 8.4$ & $161.4 \pm 7.1$ \\
\hline Teaching hospital $(\%)^{*}$ & 87.3 & 94.3 & 90.7 \\
\hline Urban hospital (\%)* & 98.2 & 99.0 & 97.8 \\
\hline \multicolumn{4}{|l|}{ Hospital bedsize (\%)* } \\
\hline Small & 6.1 & 3.0 & 5.4 \\
\hline Medium & 7.9 & 17.4 & 11.4 \\
\hline Large & 86.0 & 79.6 & 83.2 \\
\hline \multicolumn{4}{|l|}{ Hospital region (\%) ${ }^{*}$} \\
\hline Northeast & 13.1 & 15.2 & 18.2 \\
\hline Midwest or North Central & 18.5 & 18.8 & 25.7 \\
\hline South & 36.7 & 42.1 & 30.7 \\
\hline West & 31.7 & 23.9 & 25.4 \\
\hline \multicolumn{4}{|l|}{ Discharge outcomes } \\
\hline Any complication $(\%)^{*} \dagger$ & 3.4 & 6.0 & 5.6 \\
\hline Hematoma, hemorrhage, or infarction & 1.1 & 3.3 & 1.6 \\
\hline Infectious complications, procedural & 0.1 & 0.3 & 0.0 \\
\hline Mechanical complication & 0.3 & 0.6 & 0.7 \\
\hline Lead removed & 0.3 & 0.0 & 1.9 \\
\hline Retained foreign body & 0.0 & 0.0 & 0.0 \\
\hline Deep venous thrombosis/pulmonary embolism & 0.1 & 0.0 & 0.2 \\
\hline Urinary tract infection & 1.2 & 0.6 & 0.8 \\
\hline Pneumonia & 0.0 & 0.0 & 0.0 \\
\hline Other complications & 0.6 & 0.6 & 1.2 \\
\hline
\end{tabular}


TABLE 2. Comparison between FDA-approved, HDE, and emerging indications (2002-2011) (continued)

\begin{tabular}{|c|c|c|c|}
\hline Discharge Characteristics & $\begin{array}{l}\text { FDA-Approved } \\
\text { Indications }\end{array}$ & HDE Indications & $\begin{array}{l}\text { Emerging } \\
\text { Indications }\end{array}$ \\
\hline \multicolumn{4}{|l|}{ Discharge outcomes (continued) } \\
\hline \multicolumn{4}{|l|}{ Discharge disposition (\%) ${ }^{*}$} \\
\hline Routine discharge & 89.2 & 94.1 & 88.1 \\
\hline Short-term hospital transfer & 0.1 & 0.5 & 0.2 \\
\hline Other transfer (includes a skilled nursing facility) & 5.6 & 3.0 & 6.6 \\
\hline Home health care & 4.8 & 2.4 & 5.1 \\
\hline Against medical advice & $<0.1$ & 0.0 & 0.0 \\
\hline Died & 0.2 & 0.0 & 0.0 \\
\hline Alive, destination unknown & $<0.1$ & 0.0 & 0.0 \\
\hline Discharges not to home & 6.0 & 3.5 & 6.8 \\
\hline Mean LOS \pm SEM* & $2.0 \pm<0.1$ & $2.3 \pm 0.2$ & $2.9 \pm 0.2$ \\
\hline Mean postprocedure LOS \pm SEM $\S$ & $1.8 \pm<0.1$ & $2.2 \pm 0.2$ & $2.6 \pm 0.2$ \\
\hline Mean total charges \pm SEM (2011 dollars) ${ }^{*}$ & $\$ 62,077 \pm \$ 508$ & $\$ 88,173 \pm \$ 3557$ & $\$ 78,523 \pm \$ 2742$ \\
\hline Mean admission charges/day \pm SEM ${ }^{*}$ & $\$ 44,652 \pm \$ 385$ & $\$ 51,856 \pm \$ 1986$ & $\$ 42,448 \pm \$ 1546$ \\
\hline
\end{tabular}

insurance under Medicare, and any complications (Table 3). A higher hospital caseload was weakly associated with fewer non-home discharges (OR 0.99 per 1 case; 95\% CI 0.98-0.998; $\mathrm{p}<0.0082)$.

\section{LOS and Total Charges}

Those patients undergoing DBS for HDE and emerging indications had longer postprocedure LOS (2.2 and 2.6 vs 1.8 days; $p<0.0001$ ), and an emerging indication was an independent risk factor for increased LOS in the multivariate analysis (+10.6\%; 95\% CI 7.6\%-13.6\%; p < 0.0001). The occurrence of any complication was strongly associated with increased LOS (+46.7\%; 95\% CI 42.2\%-51.4\%; $\mathrm{p}<0.0001)$. Patient characteristics that increased the LOS included age $(+0.09 \%$ per year; $95 \%$ CI $0.04-0.15 \%$; $\mathrm{p}=$ $0.0011)$ and comorbidity score $(+1.4 \%$ per point; $95 \% \mathrm{CI}$ $0.8 \%-2.0 \% ; \mathrm{p} \leq 0.0001)$. Male sex was weakly protective $(-2.0 \% ; 95 \% \mathrm{CI}-3.2$ to $-0.8 \% ; \mathrm{p}=0.0011)$. Northeastern and Midwestern hospitals demonstrated increased LOS (+10.8\%; 95\% CI 3.4\%-18.6\%, p < 0.0034; and $+10.3 \%$; $95 \%$ CI $3.2 \%-17.9 \%, \mathrm{p}=0.0038$, respectively).

Total hospital charges were significantly higher for HDE and emerging indications $(\$ 88,173 \pm \$ 3557$ and $\$ 78,523 \pm \$ 2742$, respectively) than for FDA-approved indications $(\$ 62,077 \pm \$ 508 ; \mathrm{p}<0.0001)$. The difference was driven almost entirely by the LOS, as there was no significant difference in the charges per day.

\section{Discussion}

DBS for HDE and emerging indications has grown rapidly over the last decade as the procedure has been adopted to treat a wide array of diseases. The hospitals leading the charge tended to have more neurosurgeons and neurolo- gists locally, but were not necessarily those with the most DBS experience. Patients were on average younger and healthier but had a higher rate of reported complications, longer mean LOS, and greater total charges than those treated for PD or ED.

\section{Rapid Growth of HDE and Emerging Indications}

This study quantifies the rate of adoption of DBS for new indications in a cross-section of nationwide discharges. Improved understanding of brain networks and their dysfunction in neurological and psychiatric disease has led to numerous new targets for DBS and a tide of reports, largely from academic medical centers. ${ }^{20,24}$ As the results demonstrate, this enthusiasm has led to significant rates of adoption nationally for a number of disorders.

The most popular new indications included dystonia and other movement disorders, pain, the late effects of cerebrovascular disease, multiple sclerosis, tics, and depression. Not surprisingly, the greatest growth has occurred in DBS for dystonia, which received HDE status in 2003 and has been shown to be effective in numerous non-FDA application trials. ${ }^{27-29,31,32,45,59,60}$ The next largest category-other movement disorders - represents a heterogenous group of conditions, many with similar phenotypes to primary PD, ET, and primary dystonia, but were not included in the original device approvals or HDE. ${ }^{40}$ These are technically investigational or off-label indications that have not met the standards of evidence required by the FDA, but may share similar therapeutic targets and mechanisms of the action. Those patients with primary diagnoses of "cerebrovascular disease (late effects)" and multiple sclerosis could have been treated for either pain or movement disorder symptoms, as both have been reported, ${ }^{25,47,55}$ although 


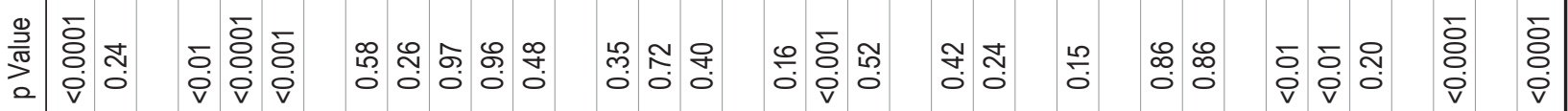

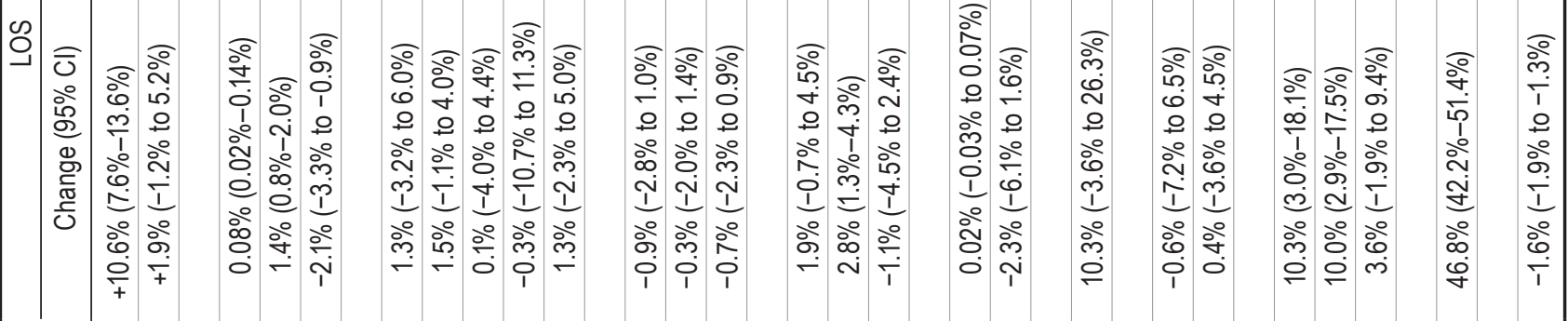

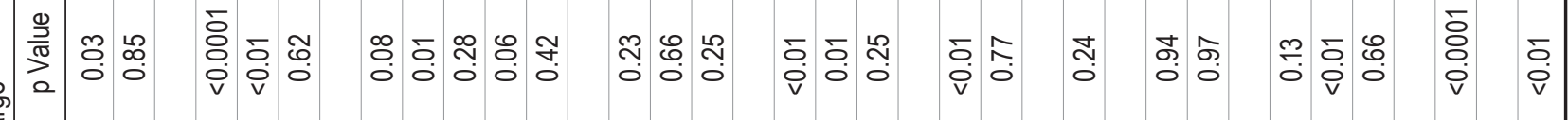

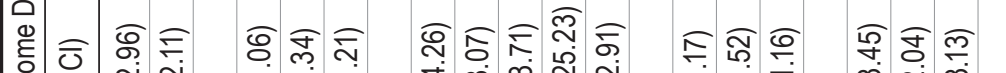

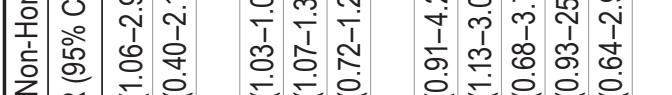

魚

送这这

กิ

e

i.

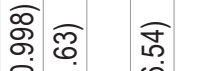

ลิธ

बํำ

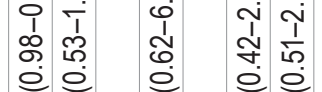

o

过

항

눈 웅을

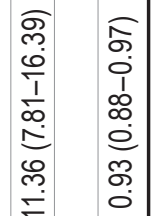

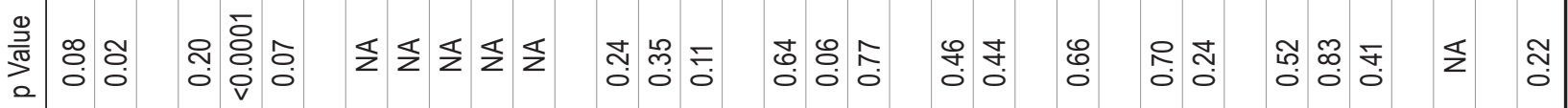

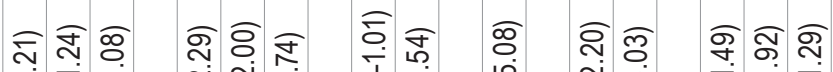

产

尊

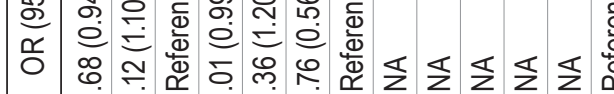

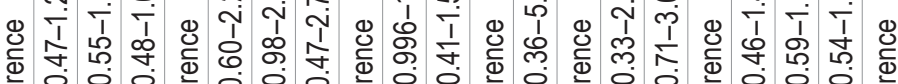

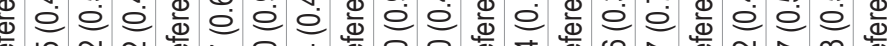

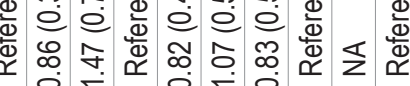

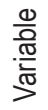

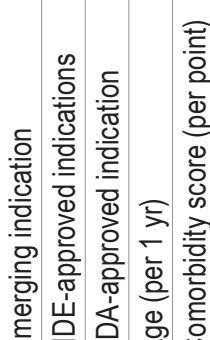

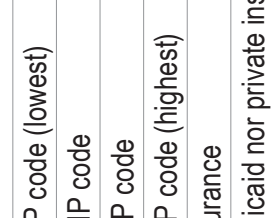

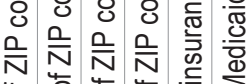

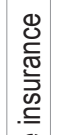

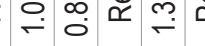

(1)

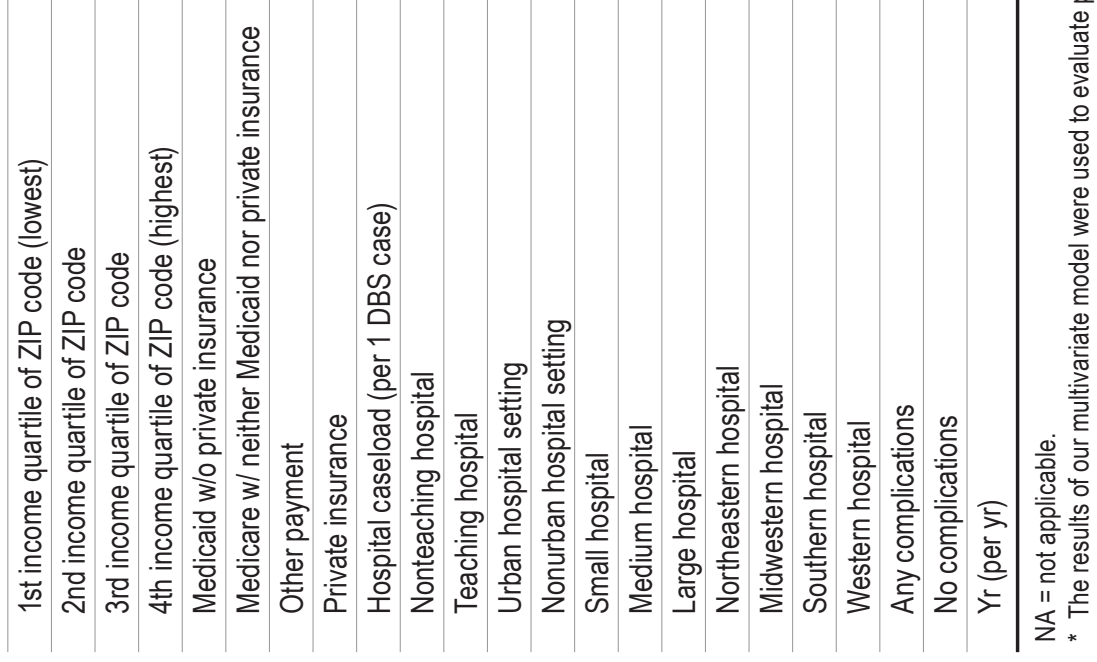


the prevalence of these indications was surprising given the limited case reports in the literature.

The NIS query also captured small numbers of most other indications that have been reported in the literature, largely in the context of pilot studies and ongoing trials, including OCD, Alzheimer's disease, conduct disorder, obesity, and tinnitus. The rarity of these cases makes the extrapolation to national estimates more subject to sampling error, as a few centers performing these procedures but not captured in the NIS data set could change the estimates significantly. Notable reported indications not captured in the data set include anorexia, ${ }^{34}$ substance addiction, ${ }^{42}$ and dementia or cognitive decline. ${ }^{19,33}$

\section{High-Volume Teaching Hospitals}

Overall, the DBS caseloads were highest at hospitals that performed DBS for OCD, depression, and dystonia, suggesting that the most experienced centers are leading the adoption of HDE and investigational indications. It is somewhat concerning, however, that DBS is being performed at lower-than-average volume centers for other indications such as pain and the late effects of cerebrovascular disease. This finding would suggest an unexpected trend of off-label DBS at less experienced centers. Historical results suggest that the surgical caseload is particularly important during the early development of a procedure. The shortage of larger studies on emerging indications argues for better data collection through either centralization at high-volume centers or registries.

\section{Younger and Healthier Patients}

The finding that patients with emerging indications were younger with below average comorbidity scores is confounded by the variation in diseases being treated, but may reflect a bias in patient selection as new indications are adopted. The younger and healthier patient population may partially reflect the earlier onset of diseases with emerging indications in comparison with PD and ET, which tend to affect the elderly. Dystonia, tics, multiple sclerosis, OCD, and depression tend to have earlier onsets. However, even the oldest, new patient populations undergoing DBS - those with other movement disorders and the late effects of cerebrovascular disease-were, on average, younger than the PD and ET patients. It is not surprising that surgeons would select younger and healthier candidates for new or experimental operations. Historically, the average age of PD and ET patients undergoing DBS has been increasing since its introduction, ${ }^{12,39}$ as has been the case for numerous other surgical procedures, as techniques become refined and risks are reduced..$^{16,23,54}$ When evaluating early outcomes data on using DBS for new indications, the possibility of selection bias should be taken into consideration.

\section{Higher Reported Complication Rates}

The higher reported complication rates with DBS for HDE and emerging indications may reflect reporting bias, with closer scrutiny applied to these emerging indications, perhaps in the setting of closely monitored studies. However, certain findings nonetheless warrant further attention.
The higher reported rates of hemorrhage or infarction for HDE and emerging indications may reflect reporting bias, but the rate was notably higher for dystonia (3.3\%) than any other indication. A higher hemorrhage rate could plausibly reflect greater risk targeting the globus pallidus (the most common target in dystonia), less familiarity with new targets and trajectories, or some unmeasured or unknown associated risk factors in these patients.

Higher rates of lead removal also contributed to the elevated reported complication rate for emerging indications. Removal on the same admission as implantation was particularly high following DBS for pain and the sequelae of cerebrovascular disease. This difference likely reflects stimulation trials and elective removal due to the lack of efficacy or untoward stimulation effects.

\section{Increased LOS for New Indications}

Patients undergoing DBS for HDE and emerging indications had longer postprocedure LOS (2.2 and 2.6 vs 1.8 days; $\mathrm{p}<0.0001$ ), and emerging indication was an independent risk factor for increased LOS in the multivariate analysis. The underlying diseases may themselves be more complex, and postoperative management in these patients may require longer hospitalizations. However, longer LOS may also represent a learning curve or increased precaution in the management of patients with less familiar diseases or a relatively new intervention. Such precautions may be appropriate as neurosurgeons learn to manage new types of postoperative sequelae and observe patients over a slightly longer duration in order to determine the efficacy or side effects of microlesion or stimulation. Based on the experiences with PD and ET over the last decade, it is reasonable to anticipate that LOS will decrease over time as surgical and patient management techniques are refined. In the interim, it should be anticipated that treating new patient populations will necessarily carry additional costs, and this cost burden should be taken into consideration when seeking reimbursement or research funding.

\section{Future Trends}

There is reason to anticipate that the higher reported complication rate, to the extent that it reflects reality, and increased LOS seen in the HDE and emerging indications groups will reduce with time. Prior studies ${ }^{12,39}$ demonstrate that over the last 2 decades the short-term outcomes of DBS for PD and ET have been improving. In our multivariate model, each progressive year in the study period was independently associated with fewer non-home discharges and shorter LOS.

\section{Limitations}

In addition to the limitations of the conclusions discussed above, there are several general limitations to the NIS data set that could have affected the categorization and analysis of the DBS cases based on the indications. First, there is no guarantee that the primary diagnosis code was the indication for surgery. All primary diagnosis codes were considered, and only those related to plausible indications were included. Additionally, NIS is a discharge-level data set without unique patient identifiers, 
and therefore procedures that were staged across multiple discharges and reimplantations could have been counted more than once. Finally, due to the limitations of the data set, this study did not attempt to look at the outcomes beyond the point of discharge or efficacy of DBS for the various indications.

\section{Conclusions}

DBS for HDE and emerging indications has grown rapidly in the last decade. While dystonia, OCD, and depression are primarily being adopted at high-volume centers, there is a concerning pattern of off-label use at less experienced hospitals. Patients undergoing DBS for HDE and emerging indications tend to be younger and healthier than the larger PD and ET populations, possibly reflecting a selection bias that should be taken into consideration when evaluating early results. The higher reported complication rates in the $\mathrm{HDE}$ and emerging indications populations may reflect reporting bias, but a higher rate of hemorrhage in dystonia patients specifically warrants further attention. Finally, additional LOS and costs should be anticipated as new indications are adopted.

\section{References}

1. Ackermans L, Duits A, van der Linden C, Tijssen M, Schruers K, Temel Y, et al: Double-blind clinical trial of thalamic stimulation in patients with Tourette syndrome. Brain 134:832-844, 2011

2. Bartsch T, Pinsker MO, Rasche D, Kinfe T, Hertel F, Diener $\mathrm{HC}$, et al: Hypothalamic deep brain stimulation for cluster headache: experience from a new multicase series. Cephalalgia 28:285-295, 2008

3. Bewernick BH, Hurlemann R, Matusch A, Kayser S, Grubert C, Hadrysiewicz B, et al: Nucleus accumbens deep brain stimulation decreases ratings of depression and anxiety in treatment-resistant depression. Biol Psychiatry 67:110-116, 2010

4. Bewernick BH, Kayser S, Sturm V, Schlaepfer TE: Longterm effects of nucleus accumbens deep brain stimulation in treatment-resistant depression: evidence for sustained efficacy. Neuropsychopharmacology 37:1975-1985, 2012

5. Boccard SG, Pereira EA, Moir L, Aziz TZ, Green AL: Longterm outcomes of deep brain stimulation for neuropathic pain. Neurosurgery 72:221-231, 2013

6. Dehning S, Mehrkens JH, Müller N, Bötzel K: Therapyrefractory Tourette syndrome: beneficial outcome with globus pallidus internus deep brain stimulation. Mov Disord 23:1300-1302, 2008

7. Denys D, Mantione M, Figee M, van den Munckhof P, Koerselman F, Westenberg H, et al: Deep brain stimulation of the nucleus accumbens for treatment-refractory obsessivecompulsive disorder. Arch Gen Psychiatry 67:1061-1068, 2010

8. Deuschl G, Schade-Brittinger C, Krack P, Volkmann J, Schäfer H, Bötzel K, et al: A randomized trial of deep-brain stimulation for Parkinson's disease. N Engl J Med 355:896908, 2006

9. Dueck A, Wolters A, Wunsch K, Bohne-Suraj S, Mueller JU, Haessler F, et al: Deep brain stimulation of globus pallidus internus in a 16-year-old boy with severe Tourette syndrome and mental retardation. Neuropediatrics 40:239-242, 2009

10. Edwards TC, Zrinzo L, Limousin P, Foltynie T: Deep brain stimulation in the treatment of chorea. Mov Disord 27:357363,2012

11. Elixhauser A, Steiner C, Harris DR, Coffey RM: Comorbid- ity measures for use with administrative data. Med Care 36:8-27, 1998

12. Eskandar EN, Flaherty A, Cosgrove GR, Shinobu LA, Barker FG II: Surgery for Parkinson disease in the United States, 1996 to 2000: practice patterns, short-term outcomes, and hospital charges in a nationwide sample. J Neurosurg 99:863-871, 2003

13. Fisher R, Salanova V, Witt T, Worth R, Henry T, Gross R, et al: Electrical stimulation of the anterior nucleus of thalamus for treatment of refractory epilepsy. Epilepsia 51:899-908, 2010

14. Fontaine D, Lazorthes Y, Mertens P, Blond S, Géraud G, Fabre N, et al: Safety and efficacy of deep brain stimulation in refractory cluster headache: a randomized placebo-controlled double-blind trial followed by a 1-year open extension. J Headache Pain 11:23-31, 2010

15. Fridley J, Thomas JG, Navarro JC, Yoshor D: Brain stimulation for the treatment of epilepsy. Neurosurg Focus 32(3):E13, 2012

16. George EM, Tergas AI, Ananth CV, Burke WM, Lewin SN, Prendergast E, et al: Safety and tolerance of radical hysterectomy for cervical cancer in the elderly. Gynecol Oncol 134:36-41, 2014

17. Goodman WK, Foote KD, Greenberg BD, Ricciuti N, Bauer $\mathrm{R}$, Ward H, et al: Deep brain stimulation for intractable obsessive compulsive disorder: pilot study using a blinded, staggered-onset design. Biol Psychiatry 67:535-542, 2010

18. Greenberg BD, Gabriels LA, Malone DA Jr, Rezai AR, Friehs GM, Okun MS, et al: Deep brain stimulation of the ventral internal capsule/ventral striatum for obsessive-compulsive disorder: worldwide experience. Mol Psychiatry 15:64-79, 2010

19. Hamani C, McAndrews MP, Cohn M, Oh M, Zumsteg D, Shapiro CM, et al: Memory enhancement induced by hypothalamic/fornix deep brain stimulation. Ann Neurol 63:119123,2008

20. Hariz M, Blomstedt P, Zrinzo L: Future of brain stimulation: new targets, new indications, new technology. Mov Disord 28:1784-1792, 2013

21. Holtzheimer PE, Kelley ME, Gross RE, Filkowski MM, Garlow SJ, Barrocas A, et al: Subcallosal cingulate deep brain stimulation for treatment-resistant unipolar and bipolar depression. Arch Gen Psychiatry 69:150-158, 2012

22. Huff W, Lenartz D, Schormann M, Lee SH, Kuhn J, Koulousakis A, et al: Unilateral deep brain stimulation of the nucleus accumbens in patients with treatment-resistant obsessivecompulsive disorder: Outcomes after one year. Clin Neurol Neurosurg 112:137-143, 2010

23. Jafari MD, Jafari F, Halabi WJ, Nguyen VQ, Pigazzi A, Carmichael JC, et al: Colorectal cancer resections in the aging us population: a trend toward decreasing rates and improved outcomes. JAMA Surg [epub ahead of print], 2014

24. Karas PJ, Mikell CB, Christian E, Liker MA, Sheth SA: Deep brain stimulation: a mechanistic and clinical update. Neurosurg Focus 35(5):E1, 2013

25. Katayama Y, Yamamoto T, Kobayashi K, Oshima H, Fukaya C: Deep brain and motor cortex stimulation for post-stroke movement disorders and post-stroke pain. Acta Neurochir Suppl 87:121-123, 2003

26. Kennedy SH, Giacobbe P, Rizvi SJ, Placenza FM, Nishikawa Y, Mayberg HS, et al: Deep brain stimulation for treatmentresistant depression: follow-up after 3 to 6 years. Am J Psychiatry 168:502-510, 2011

27. Kiss ZH, Doig-Beyaert K, Eliasziw M, Tsui J, Haffenden A, Suchowersky O: The Canadian multicentre study of deep brain stimulation for cervical dystonia. Brain 130:28792886, 2007

28. Kleiner-Fisman G, Herzog J, Fisman DN, Tamma F, Lyons KE, Pahwa R, et al: Subthalamic nucleus deep brain stimula- 
tion: summary and meta-analysis of outcomes. Mov Disord 21 (Suppl 14):S290-S304, 2006

29. Kleiner-Fisman G, Liang GS, Moberg PJ, Ruocco AC, Hurtig HI, Baltuch GH, et al: Subthalamic nucleus deep brain stimulation for severe idiopathic dystonia: impact on severity, neuropsychological status, and quality of life. J Neurosurg 107:29-36, 2007

30. Koller WC, Lyons KE, Wilkinson SB, Troster AI, Pahwa $\mathrm{R}$ : Long-term safety and efficacy of unilateral deep brain stimulation of the thalamus in essential tremor. Mov Disord 16:464-468, 2001

31. Krause M, Fogel W, Kloss M, Rasche D, Volkmann J, Tronnier V: Pallidal stimulation for dystonia. Neurosurgery 55:1361-1370, 2004

32. Kupsch A, Benecke R, Müller J, Trottenberg T, Schneider $\mathrm{GH}$, Poewe W, et al: Pallidal deep-brain stimulation in primary generalized or segmental dystonia. N Engl J Med 355:1978-1990, 2006

33. Laxton AW, Tang-Wai DF, McAndrews MP, Zumsteg D, Wennberg R, Keren R, et al: A phase I trial of deep brain stimulation of memory circuits in Alzheimer's disease. Ann Neurol 68:521-534, 2010

34. Lipsman N, Woodside DB, Giacobbe P, Hamani C, Carter JC, Norwood SJ, et al: Subcallosal cingulate deep brain stimulation for treatment-refractory anorexia nervosa: a phase 1 pilot trial. Lancet 381:1361-1370, 2013

35. Lozano AM, Giacobbe P, Hamani C, Rizvi SJ, Kennedy SH, Kolivakis TT, et al: A multicenter pilot study of subcallosal cingulate area deep brain stimulation for treatment-resistant depression. J Neurosurg 116:315-322, 2012

36. Lozano AM, Mayberg HS, Giacobbe P, Hamani C, Craddock RC, Kennedy SH: Subcallosal cingulate gyrus deep brain stimulation for treatment-resistant depression. Biol Psychiatry 64:461-467, 2008

37. Mallet L, Polosan M, Jaafari N, Baup N, Welter ML, Fontaine D, et al: Subthalamic nucleus stimulation in severe obsessive-compulsive disorder. N Engl J Med 359:2121-2134, 2008

38. Mayberg HS, Lozano AM, Voon V, McNeely HE, Seminowicz D, Hamani C, et al: Deep brain stimulation for treatmentresistant depression. Neuron 45:651-660, 2005

39. McGovern RA, Sheehy JP, Zacharia BE, Chan AK, Ford B, McKhann GM II: Unchanged safety outcomes in deep brain stimulation surgery for Parkinson disease despite a decentralization of care. J Neurosurg 119:1546-1555, 2013

40. Medtronic: Deep Brain Stimulation for Movement Disorders: Indications, Safety, and Warnings. (http:// professional.medtronic.com/pt/neuro/dbs-md/ind) [Accessed October 8, 2015]

41. Mukherjee D, Zaidi HA, Kosztowski T, Chaichana KL, Brem $\mathrm{H}$, Chang DC, et al: Disparities in access to neuro-oncologic care in the United States. Arch Surg 145:247-253, 2010

42. Müller UJ, Voges J, Steiner J, Galazky I, Heinze HJ, Möller M, et al: Deep brain stimulation of the nucleus accumbens for the treatment of addiction. Ann N Y Acad Sci 1282:119-128, 2013

43. Nuttin B, Cosyns P, Demeulemeester H, Gybels J, Meyerson B: Electrical stimulation in anterior limbs of internal capsules in patients with obsessive-compulsive disorder. Lancet 354:1526, 1999

44. Ooms P, Mantione M, Figee M, Schuurman PR, van den Munckhof P, Denys D: Deep brain stimulation for obsessivecompulsive disorders: long-term analysis of quality of life. J Neurol Neurosurg Psychiatry 85:153-158, 2014

45. Ostrem JL, Racine CA, Glass GA, Grace JK, Volz MM, Heath SL, et al: Subthalamic nucleus deep brain stimulation in primary cervical dystonia. Neurology 76:870-878, 2011

46. Pahwa R, Lyons KE, Wilkinson SB, Tröster AI, Overman J, Kieltyka J, et al: Comparison of thalamotomy to deep brain stimulation of the thalamus in essential tremor. Mov Disord 16:140-143, 2001

47. Pereira EA, Aziz TZ: Neuropathic pain and deep brain stimulation. Neurotherapeutics 11:496-507, 2014

48. Savica R, Stead M, Mack KJ, Lee KH, Klassen BT: Deep brain stimulation in tourette syndrome: a description of 3 patients with excellent outcome. Mayo Clin Proc 87:59-62, 2012

49. Schlünzen L, Vafaee MS, Cold GE, Rasmussen M, Nielsen JF, Gjedde A: Effects of subanaesthetic and anaesthetic doses of sevoflurane on regional cerebral blood flow in healthy volunteers. A positron emission tomographic study. Acta Anaesthesiol Scand 48:1268-1276, 2004

50. Schuepbach WM, Rau J, Knudsen K, Volkmann J, Krack P, Timmermann L, et al: Neurostimulation for Parkinson's disease with early motor complications. N Engl J Med 368:610-622, 2013

51. Schuurman PR, Bosch DA, Bossuyt PM, Bonsel GJ, van Someren EJ, de Bie RM, et al: A comparison of continuous thalamic stimulation and thalamotomy for suppression of severe tremor. N Engl J Med 342:461-468, 2000

52. Schuurman PR, Bosch DA, Merkus MP, Speelman JD: Longterm follow-up of thalamic stimulation versus thalamotomy for tremor suppression. Mov Disord 23:1146-1153, 2008

53. Servello D, Porta M, Sassi M, Brambilla A, Robertson MM: Deep brain stimulation in 18 patients with severe Gilles de la Tourette syndrome refractory to treatment: the surgery and stimulation. J Neurol Neurosurg Psychiatry 79:136-142, 2008

54. Sharma M, Sonig A, Ambekar S, Nanda A: Discharge dispositions, complications, and costs of hospitalization in spinal cord tumor surgery: analysis of data from the United States Nationwide Inpatient Sample, 2003-2010. J Neurosurg Spine 20:125-141, 2014

55. Starr PA: Deep brain stimulation for other tremors, myoclonus, and chorea. Handb Clin Neurol 116:209-215, 2013

56. Stolze H, Kuhtz-Buschbeck JP, Drücke H, Jöhnk K, Illert M, Deuschl G: Comparative analysis of the gait disorder of normal pressure hydrocephalus and Parkinson's disease. J Neurol Neurosurg Psychiatry 70:289-297, 2001

57. Tasker RR: Deep brain stimulation is preferable to thalamotomy for tremor suppression. Surg Neurol 49:145-154, 1998

58. Torres CV, Sola RG, Pastor J, Pedrosa M, Navas M, GarcíaNavarrete E, et al: Long-term results of posteromedial hypothalamic deep brain stimulation for patients with resistant aggressiveness. J Neurosurg 119:277-287, 2013

59. Valldeoriola F, Regidor I, Mínguez-Castellanos A, Lezcano E, García-Ruiz P, Rojo A, et al: Efficacy and safety of pallidal stimulation in primary dystonia: results of the Spanish multicentric study. J Neurol Neurosurg Psychiatry 81:6569,2010

60. Vidailhet M, Vercueil L, Houeto JL, Krystkowiak P, Benabid AL, Cornu P, et al: Bilateral deep-brain stimulation of the globus pallidus in primary generalized dystonia. N Engl J Med 352:459-467, 2005

61. Weaver FM, Follett K, Stern M, Hur K, Harris C, Marks WJ $\mathrm{Jr}$, et al: Bilateral deep brain stimulation vs best medical therapy for patients with advanced Parkinson disease: a randomized controlled trial. JAMA 301:63-73, 2009

62. Whiting DM, Tomycz ND, Bailes J, de Jonge L, Lecoultre V, Wilent B, et al: Lateral hypothalamic area deep brain stimulation for refractory obesity: a pilot study with preliminary data on safety, body weight, and energy metabolism. J Neurosurg 119:56-63, 2013

63. Wilcox RA, Cole MH, Wong D, Coyne T, Silburn P, Kerr G: Pedunculopontine nucleus deep brain stimulation produces sustained improvement in primary progressive freezing of gait. J Neurol Neurosurg Psychiatry 82:1256-1259, 2011

64. Williams A, Gill S, Varma T, Jenkinson C, Quinn N, Mitch- 
ell R, et al: Deep brain stimulation plus best medical therapy versus best medical therapy alone for advanced Parkinson's disease (PD SURG trial): a randomised, open-label trial.

Lancet Neurol 9:581-591, 2010

\section{Disclosures}

The authors report no conflict of interest concerning the materials or methods used in this study or the findings specified in this paper.

\section{Author Contributions}

Conception and design: all authors. Acquisition of data: Younger- man, Chan. Analysis and interpretation of data: Youngerman, Chan, McKhann, Sheth. Drafting the article: Youngerman, Chan, Mikell. Critically revising the article: Youngerman, Mikell, Sheth. Reviewed submitted version of manuscript: all authors. Approved the final version of the manuscript on behalf of all authors: Youngerman. Statistical analysis: Youngerman, Chan. Administrative/technical/material support: Mikell, McKhann, Sheth. Study supervision: McKhann, Sheth.

\section{Correspondence}

Brett E. Youngerman, Department of Neurological Surgery, The Neurological Institute, 710 W. 168th St., New York, NY 10032. email: bey2103@cumc.columbia.edu. 